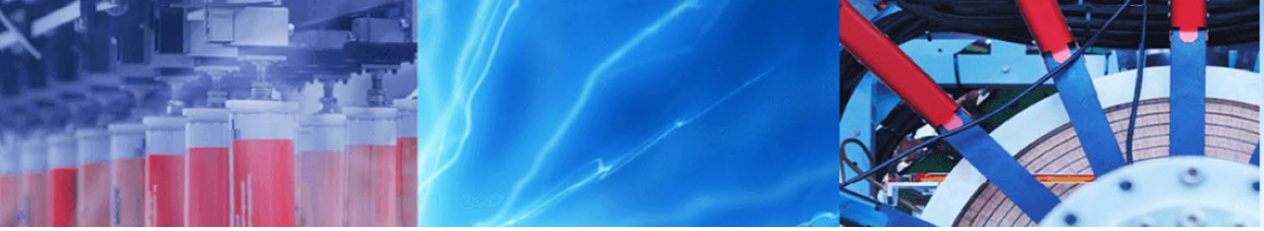

Review Paper

\title{
Assessment of endogenous fibrinolysis in clinical practice using novel tests: ready for clinical roll-out?
}

\author{
Ying X. Gue ${ }^{1,2}$ (D) Wern Yew Ding ${ }^{1} \cdot$ Gregory Y. H. Lip ${ }^{1,3} \cdot$ Diana A. Gorog ${ }^{2,4}$
}

Received: 23 December 2020 / Accepted: 17 March 2021 / Published online: 1 April 2021

(C) The Author(s) 2021 OPEN

\begin{abstract}
The occurrence of thrombotic complications, which can result in excess mortality and morbidity, represent an imbalance between the pro-thrombotic and fibrinolytic equilibrium. The mainstay treatment of these complications involves the use of antithrombotic agents but despite advances in pharmacotherapy, there remains a significant proportion of patients who continue to remain at risk. Endogenous fibrinolysis is a physiological counter-measure against lasting thrombosis and may be measured using several techniques to identify higher risk patients who may benefit from more aggressive pharmacotherapy. However, the assessment of the fibrinolytic system is not yet accepted into routine clinical practice. In this review, we will revisit the different methods of assessing endogenous fibrinolysis (factorial assays, turbidimetric lysis assays, viscoelastic and the global thrombosis tests), including the strengths, limitations, correlation to clinical outcomes of each method and how we might integrate the assessment of endogenous fibrinolysis into clinical practice in the future.
\end{abstract}

Keywords Endogenous fibrinolysis · Clinical assessment · Adverse outcomes

\section{Background}

The occurrence of thrombotic complications, that may be associated with excess mortality and morbidity, represent an imbalance between the pro-thrombotic and fibrinolytic equilibrium. In the treatment of cardiovascular disease such as acute coronary syndrome (ACS) and atrial fibrillation (AF), the use of antithrombotic therapy to prevent further major adverse cardiovascular events (MACE) is an integral component of secondary prevention. However, despite advances in pharmacotherapy, many patients remain at risk of further thrombotic events.

Endogenous fibrinolysis, if impaired, has been identified as a novel risk factor for future adverse events $[1,2]$. Biologically, the presence of impaired fibrinolysis makes perfect sense as a risk factor beyond pro-thrombotic drivers as the two processes go hand-in-hand to prevent thrombotic and haemorrhagic events. Nonetheless, the complex and dynamic nature of the thrombotic and fibrinolytic pathways (Fig. 1) can make the assessment, interpretation and clinical application challenging and there is no accepted "gold standard" test in routine clinical use.

A typical evaluation of a process involves an assessment of 3 parts-appraising the input (thrombus), the process (endogenous fibrinolysis) and the product (fibrin degradation product [FDP]) (Fig. 2a). Any evaluation of the output requires a concurrent assessment of the input, for example, the more thrombus at the start, the higher the levels of FDP will be expected for an equally effective process (Fig. 2b). However, an assessment of in vivo thrombus burden with concurrent measurement of FDP to evaluate the efficacy of fibrinolysis is not feasible with current available techniques, although the Badimon chamber [3], which utilises a

Diana A. Gorog, d.gorog@imperial.ac.uk| ${ }^{1}$ Liverpool Centre for Cardiovascular Science, University of Liverpool and Liverpool Heart \& Chest Hospital, Liverpool, UK. ${ }^{2}$ University of Hertfordshire, Hertfordshire, UK. ${ }^{3}$ Aalborg Thrombosis Research Unit, Department of Clinical Medicine, Aalborg University, Aalborg, Denmark. ${ }^{4}$ National Heart and Lung Institute, Imperial College, Dovehouse Street, London SW3 6LY, UK. 


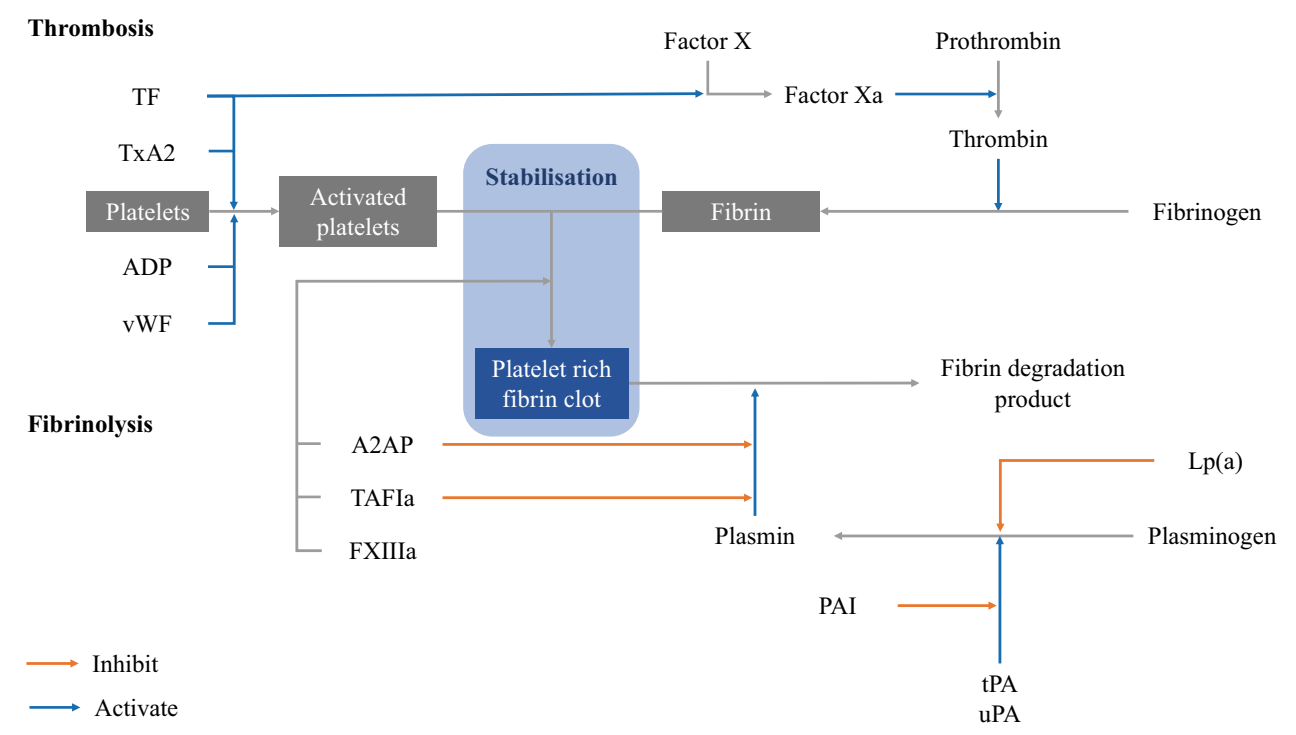

Fig. 1 Process of thrombosis and fibrinolysis. The complex process of thrombosis and fibrinolysis requires the presence of multiple factors. The formation and stabilisation of a platelet-rich fibrin clot requires (1) the activation of platelets with the help of tissue factor (TF), thromboxane A2 (TXA2), adenosine diphosphate (ADP) and von Willebrand factor (VWF) all of which are present during endothelial injury and presence of high shear stress and (2) the activation of fibrinogen to fibrin which is driven by thrombin formation, triggered by activated Factor $X$ through the common pathway of the coagulation cascade. On the other hand, fibrinolysis is mainly driven by plasmin. The activation of plasmin requires tissue (tPA) and urokinase (uPA) plasminogen activator. Inhibitors of fibrinolysis works on different segments of the pathway-plasminogen activator inhibitor (PAI) inhibits tPA and UPA, lipoprotein (a) $(L p(a))$ reduces formation of plasmin from plasminogen, thrombinactivatable fibrinolysis inhibitor (TAFI) and a-2-antiplasmin (A2AP) reduces binding of plasmin to fibrin clot and in combination with Factor XIII (FXIII), they strengthen and stabilises the fibrin clot, making it more resistant to lysis

(A)
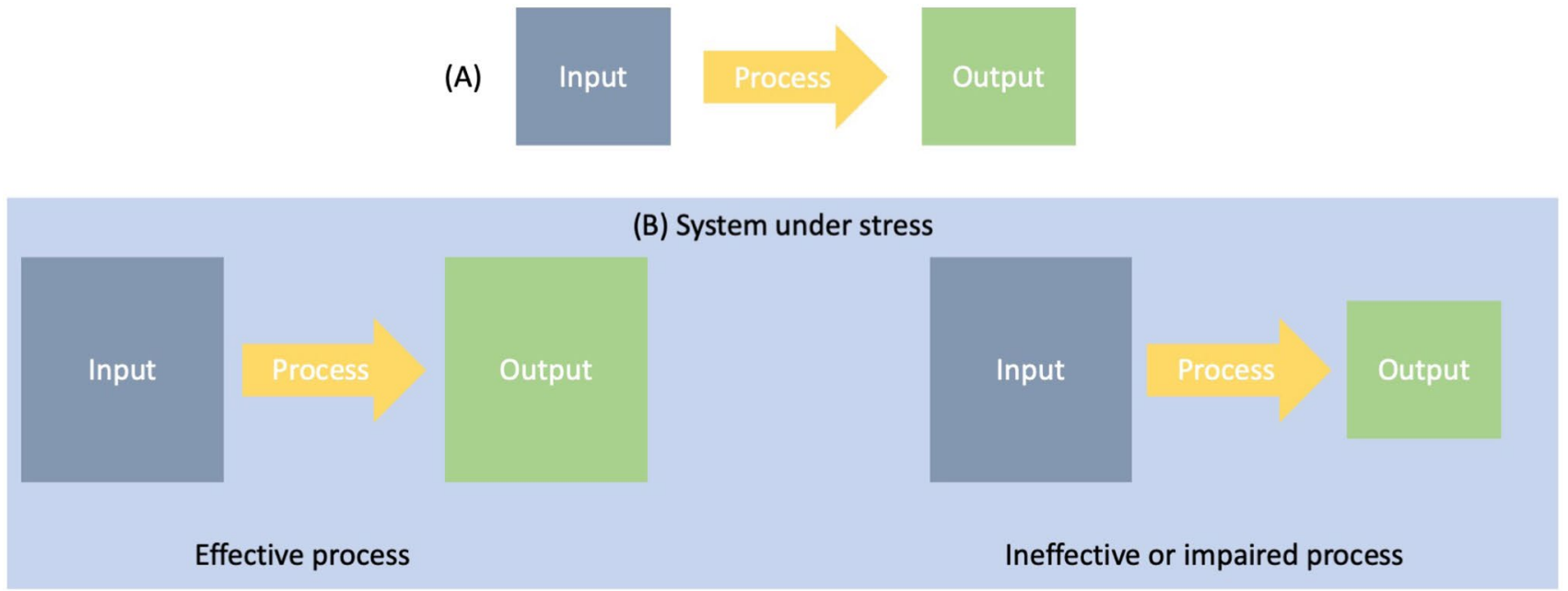

Fig. 2 Assessment of the effectiveness of a process. a Effectiveness of a process is measured by the output which is dependent on the input. b During period of stress, an effective process will be able to produce a higher output with the same volume of input when compared to an ineffective process. In biological systems, the effectiveness of the system to cope with stress (e.g. higher thrombatic burden) decides the outcome (thrombatic compliacations versus no complications)

to measuring factors involved in the process (factorial assays) or utilising ex vivo methods to replicate in vivo conditions in order to assess its efficacy. chamber, is currently the most well recognised method to assess thrombogenicity, it remains only a surrogate measure of thrombus burden. Therefore, we are limited

\section{SN Applied Sciences}




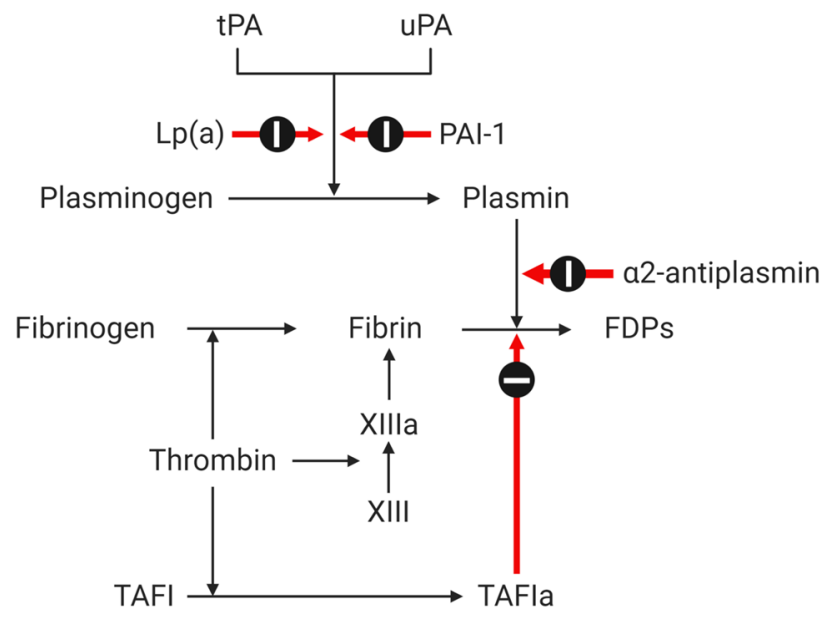

Fig. 3 Effects of different factors on the process of fibrinolysis. FDP_fibrin degradation product, Lp(a)-Lipoprotein A, PAI-1plasminogen activator inhibitor 1, TAFI-thrombin activatable fibrinolysis inhibitor, tPA-tissue plasminogen activator, uPAurokinase plasminogen activator

In this review, we will discuss currently available assessments for endogenous fibrinolysis, their clinical relevance, limitations and the future directions.

\section{Regulation of endogenous fibrinolysis}

There are many factors which play a vital role in the process of thrombosis and fibrinolysis. As the review is centred around endogenous fibrinolysis, we will focus on the factors of the fibrinolytic pathway (Fig. 3).

The key enzyme that degrades fibrin clots is plasmin which is released as a proenzyme (plasminogen) by the liver [4]. Activation of the inactive plasminogen to its active form is facilitated by tissue plasminogen activator (t-PA) and urokinase plasminogen activator. This constitutes the main pathway of fibrinolysis which is regulated by other enzymes. Tissue plasminogen activator is continually released by vascular endothelial cells into the circulation and cleared by the liver. [5] It has a half-life of approximately three minutes. Under normal physiological situations, the activation of plasminogen to plasmin by t-PA is insignificant. However, in the presence of a fibrin clot (which offers binding sites to both molecules), the activity levels of t-PA are increased by at least 500-fold [6].

Normally, free t-PA forms a complex with plasminogen activator inhibitor-1 (PAI-1), rendering it inactive thereby reducing the activation of plasminogen. Acting on processes further down the line, thrombin-activatable fibrinolysis inhibitor (TAFI) down-regulates fibrinolysis by reducing the binding of plasminogen to the fibrin clot via removal of $\mathrm{C}$-terminal lysine binding site. This halts the propagation phase of fibrinolysis through a positive feedback loop whereby plasmin generates more C-terminal lysine which in turn propagates more plasmin formation [7]. Another inhibitor of fibrinolysis is alpha-2-antiplasmin (A2AP) which works by inhibiting circulating plasmin through formation of a 1:1 stable complex [8].

Lipoprotein (a) $[L p(a)]$ is a low-density lipoprotein containing apolipoprotein(a) which shows a high degree of sequence identity with plasminogen. This homology allows $L p(a)$ to compete with plasminogen for binding to fibrin, exerting an anti-fibrinolytic effect [9].

\section{Factorial assays}

Enzymatic measurements using factorial assays comprise of two main forms-immunological assays for the quantification of specific proteins using enzyme-linked immunosorbent assay (ELISA) techniques, and functional assays to evaluate activity levels associated with these proteins within a sample. Most clinical studies on fibrinolysis have utilised one assay method. Here, we summarise some of the studies which have been performed in this area over the past decade.

\subsection{Tissue plasminogen activator}

Tissue plasminogen activator may exist as either free t-PA or, due to the high affinity of PAI-1 for t-PA, for the main part as inactivated t-PA/PAI-1 complex. Over the years, laboratory evaluation of this enzyme has proved challenging as t-PA and PAI- 1 exhibit diurnal and seasonal variations $[10,11]$, and are influenced by factors such as exercise. Therefore, standardisation of blood collection is mandatory to produce accurate results. Samples should typically be taken from a rested, fasting subject in the morning with no consumption of tobacco or alcohol beforehand. For functional assays of enzyme activity, free t-PA in the blood must be stabilised by drawing the sample into an acidified citrate solution to prevent in vitro inactivation of free t-PA by active PAI-1 [12]. Total t-PA that represents both active and inactive fractions may be measured using ELISA. In the resting state, majority of t-PA is in the inactive form.

Kulwas et al. found that ELISA-measured t-PA was raised in patients with type 2 diabetes mellitus (DM) compared to age-matched controls [13]. However, the authors reported that among those with type $2 \mathrm{DM}$, a lower concentration of $t$-PA was seen in patients with diabetic foot syndrome. A community-based cohort study of 8265 participants based in Netherlands did not demonstrate any relationship between baseline t-PA levels and incident AF over a 10-year follow-up period [14]. Nonetheless, elevated levels of t-PA were described in patients with an acute coronary 
syndrome compared to healthy controls [15]. Moreover, there was a gradual reduction in t-PA over 30 days after the acute event which is in alignment with our understanding of prothrombotic states in this setting. In patients with an acute ischaemic stroke, there was a weak but independent positive association between levels of t-PA antigen and vascular death [16]. A prospective study of 3358 middle-aged males by Wannamethee et al. failed to demonstrate any relationship between IPA and stroke risk over a 9-year follow-up period [17]. Limitations of this study were the lack of generalisability to females, younger males and other ethnic groups (predominantly Caucasian population), and the use of a single measurement of t-PA at baseline.

Surprisingly, the use of t-PA-ROTEM, which is the addition of recombinant t-PA to whole blood assays analysed by thromboelastometry (discussed later in the review), did not detect enhanced fibrinolytic capacity in patients with mild bleeding symptoms. Instead, the results were influenced by other factors such as PAI-1, TAFI, a2-antiplasmin, plasminogen, FII and FXII levels. [18] The latter finding highlights the limitations of studies that utilise immunological assays and evaluate fibrinolytic enzymes in isolation as the change in individual fibrinolytic markers may not necessarily reflect the overall state of fibrinolysis. Levels of plasminogen could potentially be more reflective of hyperfibrinolysis, with lower levels associated with severe sepsis [19] although its role in impairment of fibrinolysis and coronary artery disease remains uncertain.

\subsection{Plasminogen activator inhibitor-1}

Another important factorial assay of the fibrinolysis pathway is PAI-1. The performance of PAI-1 as a biomarker has been reported to be comparable to established clinicallyutilised biomarkers such as NT-proBNP and C-reactive protein [20]. Nonetheless, PAI-1 may be affected by various external factors. Moreover, peripheral plasma levels of PAl-1 may not reflect its true contribution to inhibiting fibrinolysis as the majority of PAI- 1 is released at the site of thrombus by activated platelets [21]. Elevated levels of PAl- 1 are observed in conditions such as obesity and metabolic disorder [22]. Both of these conditions have been independently related to hypertension, dyslipidaemia, coronary artery disease and atrial fibrillation which further supports the association between PAl-1 and various cardiovascular pathologies [23]. However, the effects of PAl-1 on long-term outcomes remain ill-defined. It was previously reported to be linked to impaired fibrinolysis in prothrombotic events such as myocardial infarction and stroke [24, 25]. A meta-analysis of studies in patients with atrial fibrillation (AF) found that increased circulating PAl-1 levels were significantly associated with subsequent stroke
[26]. However, the results of this analysis were based on only two studies.

Another area which has received some attention is the evaluation of PAI- 1 in patients undergoing percutaneous coronary intervention. Jung et al. demonstrated that raised PAl-1 was independently associated with higher rates of unplanned early revascularisation ( $<30$ days) but reduced rates of unplanned late revascularisation (30 days to 1 year) following percutaneous coronary intervention [27]. The authors postulate that the former observation may be related to the fact that PAI-1 levels are a surrogate for platelet activation which is enhanced in the acute phase [27]. Additionally, excess PAI-1 has been associated with lysis-resistant thrombus [28]. Based on the studies above, PAI-1 levels may have differing implications in specific cohorts and clinical situations. Overall, the role of PAI1 as a biomarker has the same pitfall as t-PA - when measured in isolation from other factors, its value is limited.

Several studies have investigated the role PAI-1 4G/5G polymorphism in the promoter region of chromosome 7q22. This mutation is associated with an increased expression of PAI-1. Compared to carriers of homozygous phenotypes ( $4 \mathrm{G} / 4 \mathrm{G}$ or $5 \mathrm{G} / 5 \mathrm{G}$ ), myocardial infarction patients with PAI-1 4G/5G polymorphism were more likely to have coronary artery occlusion. Indeed, a meta-analysis of 72 studies which included 45,083 patients found that the PAI-1 4G/5G polymorphism was associated with earlyonset coronary artery disease and significantly increased the risk of myocardial infarction in both Caucasians and Asians [29]. In contrast, the PAI-1 5G/5G genotype was independently linked to early spontaneous recanalization of the infarct-related artery in patients who presented with ST-elevation myocardial infarction [30].

On a separate but related topic, higher levels of PAI-1 were found to be correlated to decreased low density lipoprotein particle size, which in turn increases the risk of atherosclerotic cardiovascular disease [22, 31]. Plasma concentration of PAI- 1 has been found to be reduced with drug therapies such as atorvastatin and empagliflozin $[32,33]$. This may provide an interesting avenue for future research.

\subsection{Thrombin-activatable fibrinolysis inhibitor}

In a study of female patients, those with prior gestational DM had increased levels of atherosclerotic biomarkers and carotid intima media thickness compared to controls but no difference in TAFI antigen levels [34]. A further study involving a subgroup of patients with AF on oral anticoagulation also demonstrated similar TAFI antigen levels between patients with and without DM. Despite this, the authors found that patients with DM who were treated with insulin had a hypercoagulable state secondary to 
higher levels of thrombin generation. Ząbczyk et al. showed that patients with left ventricular thrombus had hypofibrinolysis with higher TAFI antigen levels alongside enhanced thrombin generation and more compact fibrin clots compared to controls. A case-controlled study of Chinese patients demonstrated a definite correlation between TAFI antigen levels and stroke risk in this population [35]. However, there was a complex relationship such that with the increase of TAFI levels, the relative risk of stroke first increased then decreased. TAFI antigen may also be related to excess prothrombotic complications typically observed in malignancy [36].

TAFI is encoded by the carboxypeptidase B2 (CPB2) gene and several genetic mutations have been described. In a case-controlled trial, $\mathrm{Xu}$ et al. found that at the TAFI coding gene $1040 \mathrm{C} / \mathrm{T}$, the frequency for the $\mathrm{T}$ allele was inversely linked to an increased risk of diabetic nephropathy [37]. TAFI gene polymorphisms (505G/A and $+1583 \mathrm{~T} / \mathrm{A}$ ) were associated with greater severity of coronary stenosis in patients with suspected coronary artery disease [38]. Other genetic variants such as Ala147Thr(rs3742264) and Thr325lle(rs 1926447) have also been investigated but with conflicting results $[39,40]$.

\section{4 a2-antiplasmin}

In mice models, a2-antiplasmin appeared to be essential for the formation of stasis-induced thrombus [41]. Furthermore, it had a profound, dose-related impact on ischaemic brain injury, swelling, haemorrhage and survival after cerebral thromboembolism potentially through its effects on microvascular thrombosis and expression of matrix metalloproteinase-9 [42]. Patients with type 1 DM were reported to incorporate more antiplasmin into the fibrin network than controls without DM; however, this may be counterbalanced by an increased fibrinolytic potential in plasma due to lower antiplasmin levels (and PAl- 1 activity).

Higher levels of a2-antiplasmin were also observed in patients with obstructive sleep apnoea [43]. This may partly explain the increased risk of cardiovascular complications often linked to this cohort, as confocal studies have revealed that greater levels of a2-antiplasmin were associated with the formation of denser fibrin clots with a decreased fibrinolytic response [44]. Interestingly, Tóth et al. found regional differences in a2-antiplasmin levels (and other markers of thrombosis and fibrinolysis) between left atrial and femoral vein samples during cardiac catheterisation [45], suggesting that systemic measures may not necessarily reflect local changes in haemostasis.

\subsection{Lipoprotein(a)}

Measurement of $L p(a)$ is typically performed using immunological methods directed at apo(a). There is growing data to support a relationship between $L p(a)$ and the risk of atherosclerotic cardiovascular disease, ischaemic stroke and venous thromboembolism. In fact, this has recently been described in detail $[46,47]$. High $L p(a)$ level has been identified as an independent risk factor of cardiovascular disease with causal links to atherosclerosis. Among patients with known coronary artery disease, it also predicts worse long-term outcomes in terms of allcause death, cardiovascular death, non-fatal myocardial infarction, stroke and in-stent restenosis $[48,49]$.

In the ARIC study cohort, elevated levels of $L p(a)$ were not associated with incident AF [50]. However, it contributed to an increased risk of stroke among non-AF patients. More recently, a study by Arora et al. confirmed that Lp(a) is indeed a risk factor for ischaemic stroke but suggested that there were racial differences of the $L p(a)$ risk multiplier in this setting [51]. Conversely, higher $L p(a)$ levels were related to a lower risk of haemorrhagic stroke among patients on peritoneal dialysis [52].

\subsection{Summary on the usefulness of measuring different components of the fibrinolytic pathway}

There have been many studies in the literature attempting to define the predictive value of different factorial assays in fibrinolysis. However, the conflicting results coupled by the limitations of this approach in terms of knowing the relative importance and contribution of individual biomarkers to the overall fibrinolytic response, the difficulty in interpretation of biomarker levels and activity, and the weak association in positive studies have resulted in much disappointment. Due to the complex nature of the fibrinolytic pathway, with complex interactions between each factor, it is understandably challenging to gain a comprehensive overview based on assessments of individual components or enzymes [53-55]. Hence, global assays of fibrinolysis may provide a better assessment of fibrinolytic status.

\section{Ex vivo assessment of fibrinolysis}

Ex vivo assessment of fibrinolysis can be performed in plasma or whole blood assays, with or without external activators. 


\subsection{Turbidimetric lysis assays}

One of the first tests for overall fibrinolytic activity of plasma was the Euglobulin Clot Lysis Test in which plasma samples were treated to form a precipitant containing plasminogen, t-PA and fibrinogen. The precipitant is then dissolved in buffer and clotted with addition of thrombin, measuring the time to clot lysis by inspection. Although it has shown correlation to factors of fibrinolysis [56], this cumbersome technique has been replaced by more modern assays. The laboratory technique for assessment of plasma clot turbidity utilises light transmission to provide a measure of fibrin clot density. Plasma samples are treated with a mix of coagulation and lysis activators to initiate the process of coagulation and fibrinolysis [1]. With the utilisation of a microplate assay, lysis time (typically recorded as time to achieve half of the maximum absorbance) can be recorded as a measure of effectiveness of fibrinolysis.

The measurement of plasma clot lysis time has been shown as an independent predictor of adverse clinical outcome in ACS as shown in the large, multicentre substudy of the PLATO trial, with a HR of $1.36(95 \% \mathrm{Cl} 1.17-1.59)$ for cardiovascular death with each $50 \%$ increase in lysis time[1] and within the diabetic population (HR 1.49, 95\% $\mathrm{Cl} 1.08-2.04$ ) [57]. In patients with AF on oral anticoagulation, clot lysis time has been shown to predict stroke, with a HR of $7.67(95 \% \mathrm{Cl} 2.78-21.17)$ when comparing the highest to the lower quartiles [58].

There are important limitations to this technique in how it reflects fibrinolysis in vivo. The main limitation of this technique is that it excludes cellular components (including platelets, neutrophils) so does not assess the contribution of these to thrombosis and fibrinolysis and also because of this, no platelet-dependent thrombus is generated, and thrombin is the main determinant of thrombosis and fibrinolysis resistance. Secondly, as the test requires addition of factors to initiate coagulation and fibrinolysis, making it insensitive to the influence of intrinsic fibrinolytic factors [59] and hence, is less of a measurement of endogenous fibrinolysis but more of assessment of response to fibrinolytic factors. Another limitation of turbidimetric assays is the requirement of trained laboratory personnel and the variation which exists between laboratories which makes it cumbersome as a routine clinical test [60].

\subsection{Viscoelastic tests}

Thromboelastography or TEG ${ }^{\circledast}$ (Haemonetics, UK) and rotational thromboelastometry or ROTEM ${ }^{\otimes}$ (Pentapharm $\mathrm{GmbH}$, Munich, Germany) are point of care, global test of coagulation status, simultaneously assessing clot development, stabilization, and dissolution based upon the same principle. These utilise a pin suspended by a torsion wire into a cylinder to measure the physical properties of a clot. As blood clot formation occurs around the pin, fibrin strands form between the cylindrical cup and pin. The rotation of the cylindrical cup will be transmitted to the pin whose displacement is then picked up by the torsion wire. This is analysed and presented in graphical form by the instrument to allow analysis of different stages of coagulation and fibrinolysis [61]. The techniques were designed to be used with native blood but modification with different activators and inhibitors have been used, [62-64] although the correlation between activated and non-activated samples has been poor [65].

Studies involving viscoelastic tests are mainly based on the prediction of bleeding (hyperfibrinolysis) and the requirement for blood and blood products in the settings of trauma resuscitation and in surgery [66-69]. Apart from maximum amplitude (MA) which is a measure of hypercoagulability [70], there has not been any studies correlating fibrinolytic assessment using viscoelastic tests and adverse outcomes.

One of the main advantages is that performing the test is relatively simple as apart from preparation of the sample, the test is fully automated, with the results recorded on the system. However, its usefulness is limited in the assessment of thrombosis risk [71, 72]. Another shortcoming, in terms of prediction of arterial thrombosis, is the employment of the low-flow, static-type situation which resembles more venous, rather than arterial thrombosis. This is less reflective of the physiological response to high shear thrombosis, which typically occurs during arterial thrombotic events.

\subsection{Global thrombosis test}

The Global Thrombosis Test (GTT) (Thromboquest Ltd., London, UK) is a relatively new automated, point-of-care test that simultaneously assesses platelet reactivity, thrombosis, and fibrinolytic activity, from a native whole blood sample [73]. Blood passing through a plastic conical tube with narrow gaps is exposed to high shear stress that mimics flow within a narrowed vessel, activates platelets and induces thrombus formation. Thrombus formation gradually reduces flow and finally causes luminal occlusion. Reduction of flow, as detected by an optical sensor, is expressed as occlusion time (OT). Blood flow resumes in response to spontaneous fibrinolysis of the thrombus, and the time taken to do so is expressed as lysis time (LT).

Clinical studies evaluating the GTT have shown a relationship between $L T$, a measure of endogenous fibrinolysis, and MACE in patients with ACS. The assessment of endogenous fibrinolysis has been shown to independently predict MACE in ACS [74]. In patients undergoing primary 
Table 1 Summary of strengths and limitations of different assessment methods

\begin{tabular}{|c|c|c|}
\hline Assessment & Strengths & Limitations \\
\hline \multicolumn{3}{|l|}{ Factorial assays } \\
\hline Antigen & $\begin{array}{l}\text { Reliable } \\
\text { Easy to perform }\end{array}$ & $\begin{array}{l}\text { Measures total antigen variably depending on antibod- } \\
\text { ies used Does not provide a true reflection of the } \\
\text { effects of measured biomarker } \\
\text { Weak association with clinical outcomes }\end{array}$ \\
\hline Activity & Measures effects of biomarkers & $\begin{array}{l}\text { Less reliable-influenced by external factors } \\
\text { Impractical (collection and storage requirements) } \\
\text { Weak association with clinical outcomes }\end{array}$ \\
\hline \multicolumn{3}{|l|}{ Ex-vivo assessment } \\
\hline Plasma turbidimetric assay & $\begin{array}{l}\text { Large studies with good correlation to clinical out- } \\
\text { come }\end{array}$ & $\begin{array}{l}\text { Plasma sample-lack of effect from blood components } \\
\text { Requires addition of coagulation and lysis activators } \\
\text { Skilled laboratory personnel required } \\
\text { Variation between different laboratories }\end{array}$ \\
\hline Viscoelastic assay & $\begin{array}{l}\text { Easy to perform-fully automated test } \\
\text { Can be performed with native whole blood or blood } \\
\text { with activators }\end{array}$ & $\begin{array}{l}\text { Low-flow, static-type more akin to venous flow } \\
\text { Limited correlation of fibrinolytic markers to clinical } \\
\text { outcomes }\end{array}$ \\
\hline Global thrombosis test & $\begin{array}{l}\text { Easy to perform-fully automated test } \\
\text { Uses native whole blood } \\
\text { Mimics high-shear test } \\
\text { Good correlation with clinical outcomes }\end{array}$ & Requires rapid processing of blood sample \\
\hline
\end{tabular}

$\mathrm{PCl}$, pre- $\mathrm{PCl}$ impaired endogenous fibrinolysis is associated with subsequent MACE (HR 9.1, 95\% Cl 4.28-15.03), [2] whilst effective (short) fibrinolysis was associated with spontaneous reperfusion as evidenced by ST-segment resolution on the ECG and angiographic Thrombolysis In Myocardial Infarction (TIMI) 3 flow pre-primary PCI [75]. The importance of endogenous fibrinolysis in patients with $A F$, in terms of predicting future ischaemic events such as stroke, has not been evaluated, apart from evaluating the effects of direct oral anticoagulants [76, 77].

The main advantage of the GTT is that it is an easy to use, point-of-care test that can assess platelet reactivity, thrombus stability and endogenous fibrinolysis, providing an overall assessment. When compared with other forms of testing for platelet function and fibrinolytic potential, the GTT has other advantages. The use of native, nonanticoagulated whole blood allows the measurement of the effects of thrombin generation in platelet aggregation without depletion of calcium (as opposed to citrated blood which is commonly required in other tests). Secondly, the presence of high shear as the key initiator of platelet activation is analogous to the physiological mechanism of platelet activation within a stenosed artery. Lastly, the assessment of spontaneous lysis through the measurement of LT is again comparable to the physiological recanalization of an occluded artery.

One of the limitations of the GTT is the requirement for rapid processing of whole blood sample as the process of coagulation will initiate without the use of anticoagulants. When compared to other assessments of fibrinolysis, the GTT produces a more global assessment which is more reflective of the pathological conditions that occur within stenosed arteries.

\section{Clinical integration and conclusion}

To integrate a test into routine clinical practice, the test must be [1] valuable in either providing diagnostic or prognostic information and [2] actionable to alter pharmacotherapy or future management. The assessment of endogenous fibrinolysis (Table 1), as shown by the studies above, has been shown to provide prognostic information in patients cardiovascular disease. Second, in the era of personalised medicine, using impaired fibrinolysis as an adverse prognostic biomarker could justify more potent pharmacotherapy that carries higher risk in some groups of patients. Therefore, there are grounds to integrate its assessment into routine clinical practice.

The assessment of endogenous fibrinolysis can play a vital role in predicting future MACE in patients with cardiovascular disease. More work will need to be done to build a more complete fibrinolytic profile for each of individual patient so we can move closer towards personalised medicine, to improve outcomes in patients with impaired fibrinolysis.

\section{Acknowledgement None}

Author contributions YXG was involved in the concept, wrote the first draft, and worked on subsequent revisions. WYD was involved 
in writing the first draft and worked on subsequent revision. GYHL was involved in the critical review and revision of the manuscript. DAG was responsible for conception, critical review and revision of manuscript.

\section{Declarations}

Conflict of interest YXG: None; WYD: None; DAG: Speaker honoraria from: AstraZeneca, Bayer, Boehringer Ingelheim; Institutional grant from Bayer.; GYHL: Consultant for Bayer/Janssen, BMS/Pfizer, Boehringer Ingelheim, Verseon and Daiichi-Sankyo. Speaker for BMS/Pfizer, Boehringer Ingelheim, and Daiichi-Sankyo. No fees are directly received personally.

Open Access This article is licensed under a Creative Commons Attribution 4.0 International License, which permits use, sharing, adaptation, distribution and reproduction in any medium or format, as long as you give appropriate credit to the original author(s) and the source, provide a link to the Creative Commons licence, and indicate if changes were made. The images or other third party material in this article are included in the article's Creative Commons licence, unless indicated otherwise in a credit line to the material. If material is not included in the article's Creative Commons licence and your intended use is not permitted by statutory regulation or exceeds the permitted use, you will need to obtain permission directly from the copyright holder. To view a copy of this licence, visit http://creativecommons. org/licenses/by/4.0/.

\section{References}

1. Sumaya W, Wallentin L, James SK, Siegbahn A, Gabrysch $\mathrm{K}$, Bertilsson $\mathrm{M}$ et al (2018) Fibrin clot properties independently predict adverse clinical outcome following acute coronary syndrome: a PLATO substudy. Eur Heart J 39(13):1078-1085

2. Farag M, Spinthakis N, Gue YX, Srinivasan M, Sullivan K, Wellsted $D$ et al (2018) Impaired endogenous fibrinolysis in ST-segment elevation myocardial infarction patients undergoing primary percutaneous coronary intervention is a predictor of recurrent cardiovascular events: the RISK PPCI study. Eur Heart J 40(3):295-305

3. Zafar MU, Santos-Gallego CG, Badimon L, Badimon JJ (2018) Badimon perfusion chamber: an ex vivo model of thrombosis. Methods Mol Biol 1816:161-171

4. Ezihe-Ejiofor JA, Hutchinson N (2013) Anticlotting mechanisms 1: physiology and pathology. Contin Educ Anaesth Crit Care Pain 13(3):87-92

5. van Hinsbergh VW (2012) Endothelium-role in regulation of coagulation and inflammation. Semin Immunopathol 34(1):93-106

6. Hoylaerts M, Rijken DC, Lijnen HR, Collen D (1982) Kinetics of the activation of plasminogen by human tissue plasminogen activator. Role fibrin J Biol Chem 257(6):2912-2919

7. Bouma BN, Mosnier LO (2006) Thrombin activatable fibrinolysis inhibitor (TAFI)-how does thrombin regulate fibrinolysis? Ann Med 38(6):378-388

8. Abdul S, Leebeek FWG, Rijken DC, Uitte de Willige S (2016) Natural heterogeneity of a2-antiplasmin functional and clinical consequences. Blood 127(5):538-545

9. Boffa MB, Koschinsky ML (2016) Lipoprotein (a): truly a direct prothrombotic factor in cardiovascular disease? J Lipid Res 57(5):745-757

SN Applied Sciences
10. Ghebre MA, Wannamethee SG, Rumley A, Whincup PH, Lowe GD, Morris RW (2012) Prospective study of seasonal patterns in hemostatic factors in older men and their relation to excess winter coronary heart disease deaths. J Thromb Haemost 10(3):352-358

11. Rudnicka AR, Rumley A, Lowe GD, Strachan DP (2007) Diurnal, seasonal, and blood-processing patterns in levels of circulating fibrinogen, fibrin D-dimer, C-reactive protein, tissue plasminogen activator, and von Willebrand factor in a 45-year-old population. Circulation 115(8):996-1003

12. Chandler WL (2019) Chapter 146 - Laboratory techniques in fibrinolysis testing. In: Shaz BH, Hillyer CD, Reyes Gil MBT (Eds.) Transfusion medicine and hemostasis. 3rd ed. Elsevier;. p. 865-8. 2019.

13. Kulwas A, Lisewska B, Jundziłł W, Ruszkowska B, Drewniak W, Ruprecht $Z$ et al (2017) Tissue plasminogen activator (t-PA) and plasminogen activator inhibitor type 1 (PAI-1) in diabetic foot syndrome. Adv Med Sci 62(1):87-91

14. Mulder BA, Geelhoed B, van der Harst P, Spronk HM, Van Gelder IC, Asselbergs FW et al (2018) Plasminogen activator inhibitor-1 and tissue plasminogen activator and incident AF: data from the PREVEND study. Int J Cardiol 272:208-210

15. Shantsila E, Montoro-García S, Tapp LD, Apostolakis S, Wrigley BJ, Lip GY (2012) Fibrinolytic status in acute coronary syndromes: evidence of differences in relation to clinical features and pathophysiological pathways. Thromb Haemost 108(1):32-40

16. Pedersen A, Redfors $P$, Lundberg L, Gils A, Declerck PJ, Nilsson S et al (2016) Haemostatic biomarkers are associated with longterm recurrent vascular events after ischaemic stroke. Thromb Haemost 116(09):537-543

17. Wannamethee SG, Whincup PH, Lennon L, Rumley A, Lowe GD (2012) Fibrin D-dimer, tissue-type plasminogen activator, von Willebrand factor, and risk of incident stroke in older men. Stroke 43(5):1206-1211

18. Vries MJ, Macrae F, Nelemans PJ, Kuiper GJ, Wetzels RJ, Bowman P et al (2019) Assessment and determinants of whole blood and plasma fibrinolysis in patients with mild bleeding symptoms. Thromb Res 174:88-94

19. Mavrommatis AC, Theodoridis T, Economou M, Kotanidou A, El Ali M, Christopoulou-Kokkinou V et al (2001) Activation of the fibrinolytic system and utilization of the coagulation inhibitors in sepsis: comparison with severe sepsis and septic shock. Intensive Care Med 27(12):1853-1859

20. Jung RG, Simard T, Di Santo P, Labinaz A, Moreland R, Duchez A-C et al (2019) Performance of plasminogen activator inhibitor- 1 as a biomarker in patients undergoing coronary angiography: analytical and biological considerations. Diab Vasc Dis Res 16(5):478-482

21. Torr-Brown SR, Sobel BE (1993) Attenuation of thrombolysis by release of plasminogen activator inhibitor type- 1 from platelets. Thromb Res 72(5):413-421

22. Iida K, Tani S, Atsumi W, Yagi T, Kawauchi K, Matsumoto $\mathrm{N}$ et al (2017) Association of plasminogen activator inhibitor-1 and lowdensity lipoprotein heterogeneity as a risk factor of atherosclerotic cardiovascular disease with triglyceride metabolic disorder: a pilot cross-sectional study. Coron Artery Dis 28(7):577-587

23. Jung RG, Simard T, Labinaz A, Ramirez FD, Di Santo P, Motazedian P et al (2018) Role of plasminogen activator inhibitor-1 in coronary pathophysiology. Thromb Res 164:54-62

24. Thögersen AM, Jansson J-Hk, Boman K, Nilsson TrK, Weinehall L, Huhtasaari F et al (1998) High plasminogen activator inhibitor and tissue plasminogen activator levels in plasma precede a first acute myocardial infarction in both men and women: evidence for the fibrinolytic system as an independent primary risk factor. Circulation 98(21):2241-2247 
25. Lindgren A, Lindoff C, Norrving B, Åstedt B, Johansson BB (1996) Tissue plasminogen activator and plasminogen activator inhibitor-1 in stroke patients. Stroke 27(6):1066-1071

26. Wu N, Chen X, Cai T, Wu L, Xiang Y, Zhang M et al (2015) Association of inflammatory and hemostatic markers with stroke and thromboembolic events in atrial fibrillation: a systematic review and meta-analysis. Can J Cardiol 31(3):278-286

27. Jung RG, Simard T, Di Santo P, Dhaliwal S, Sypkes C, Duchez A-C et al (2020) Evaluation of plasminogen activator inhibitor-1 as a biomarker of unplanned revascularization and major adverse cardiac events in coronary angiography and percutaneous coronary intervention. Thromb Res 191:125-133

28. Sambola A, Del Blanco BG, Ruiz-Meana M, Francisco J, Barrabés JA, Figueras J et al (2016) Increased von Willebrand factor, $P$-selectin and fibrin content in occlusive thrombus resistant to lytic therapy. Thromb Haemost 115(06):1129-1137

29. Zhang $H$, Dong $P$, Yang $X$, Liu Z (2014) Plasminogen activator inhibitor-1 4G/5G polymorphism is associated with coronary artery disease risk: a meta-analysis. Int J Clin Exp Med 7(10):3777

30. Cagliyan CE, Yuregir OO, Balli M, Tekin K, Akilli RE, Bozdogan ST et al (2013) Plasminogen activator inhibitor-1 5G/5G genotype is associated with early spontaneous recanalization of the infarctrelated artery in patients presenting with acute ST-elevation myocardial infarction. Coron Artery Dis 24(3):196-200

31. Pichler G, Amigo N, Tellez-Plaza M, Pardo-Cea M, DominguezLucas A, Marrachelli V et al (2018) LDL particle size and composition and incident cardiovascular disease in a South-European population: the hortega-liposcale follow-up study. Int J Cardiol 264:172-178

32. Sahebkar A, Catena C, Ray KK, Vallejo-Vaz AJ, Reiner Ž, Sechi LA et al (2016) Impact of statin therapy on plasma levels of plasminogen activator inhibitor-1. Thromb Haemost 116(07):162-171

33. Sakurai S, Jojima T, lijima T, Tomaru T, Usui I, Aso Y (2020) Empagliflozin decreases the plasma concentration of plasminogen activator inhibitor-1 (PAI-1) in patients with type 2 diabetes: association with improvement of fibrinolysis. J Diabetes Complic 34(11):107703

34. Akinci B, Celtik A, Yener S, Genc S, Tunali S, Yuksel F et al (2011) Plasma thrombin-activatable fibrinolysis inhibitor levels are not associated with glucose intolerance and subclinical atherosclerosis in women with previous gestational diabetes. Clin Appl Thromb Hemost 17(6):E224-E230

35. Dai H, Shi J, He Q, Sun H (2017) Dose-response relationship between thrombin-activatable fibrinolysis inhibitor (TAFI) and stroke: a Chinese case-control study. Med Sci Monitor Int Med J Exp Clin Res 23:4376

36. Fidan E, Kavgaci H, Orem A, Yilmaz M, Yildiz B, Fidan S et al (2012) Thrombin activatable fibrinolysis inhibitor and thrombinantithrombin-III-complex levels in patients with gastric cancer. Tumour Biol 33(5):1519-1525

37. Xu C-W, Wu X-B, Ma X-L, Wang Y-S, Zhang B-C, Zhao J-J et al (2012) Genetic variation in thrombin-activatable fibrinolysis inhibitor is associated with the risk of diabetic nephropathy. J Endocrinol Invest 35(7):620-624

38. Rattanawan C, Komanasin N, Settasatian N, Settasatian C, Kukongviriyapan U, Intharapetch P et al (2018) Association of TAFI gene polymorphisms with severity of coronary stenosis in stable coronary artery disease. Thromb Res 171:171-176

39. Shi J, Zhi P, Chen J, Wu P, Tan S (2014) Genetic variations in the thrombin-activatable fibrinolysis inhibitor gene and risk of cardiovascular disease: a systematic review and meta-analysis. Thromb Res 134(3):610-616

40. Wang S, Zhang H, Dong C, Sun H (2016) Meta-analysis of TAFI polymorphisms and risk of cardiovascular and cerebrovascular diseases. Genet Mol Res GMR. https://doi.org/10.4238/gmr. 15026718
41. Singh S, Houng AK, Reed GL (2019) Venous stasis-induced fibrinolysis prevents thrombosis in mice: role of a2-antiplasmin. Blood 134(12):970-978

42. Reed GL, Houng AK, Wang D (2014) Microvascular thrombosis, fibrinolysis, ischemic injury, and death after cerebral thromboembolism are affected by levels of circulating a2-antiplasmin. Arterioscler Thromb Vasc Biol 34(12):2586-2593

43. Zakrzewski M, Zakrzewska E, Kiciński P, Przybylska-Kuć S, Dybała A, Myśliński W et al (2016) Evaluation of fibrinolytic inhibitors: alpha-2-antiplasmin and plasminogen activator inhibitor 1 in patients with obstructive sleep apnoea. PLoS ONE 11(11):e0166725

44. Cubedo J, Padró T, Peña E, Aledo R, Formiga F, Ferrer A et al (2015) High levels of antifibrinolytic proteins are found in plasma of older octogenarians with cardiovascular disease and cognitive decline. J Am Coll Cardiol 65(24):2667-2669

45. Tóth NK, Csanádi Z, Hajas O, Kiss A, Nagy-Baló E, Kovács KB et al (2017) Intracardiac hemostasis and fibrinolysis parameters in patients with atrial fibrillation. BioMed Res Int 2017:1-10

46. Hoogeveen RC, Ballantyne CM (2020) Residual cardiovascular risk at low LDL: remnants, lipoprotein(a), and inflammation. Clin Chem 67:143-153

47. Nave AH, von Eckardstein A (2019) Is lipoprotein (a) a risk factor for ischemic stroke and venous thromboembolism? Clin Res Cardiol Suppl 14(1):28-32

48. Liu H-H, Cao Y-X, Jin J-L, Zhang H-W, Hua Q, Li Y-F et al (2020) Association of lipoprotein (a) levels with recurrent events in patients with coronary artery disease. Heart 106:1228-1235

49. Chen Z, Jiang C, Qu H, Liang S, Yang J, Wu H et al (2019) Association of lipoprotein (a) and major adverse cardiovascular events in patients with percutaneous coronary intervention. Arch Med Sci AMS 15(6):1375

50. Aronis KN, Zhao D, Hoogeveen RC, Alonso A, Ballantyne CM, Guallar E et al (2017) Associations of lipoprotein (a) levels with incident atrial fibrillation and ischemic stroke: the ARIC (Atherosclerosis Risk in Communities) Study. J Am Heart Assoc 6(12):e007372

51. Arora P, Kalra R, Callas PW, Alexander KS, Zakai NA, Wadley V et al (2019) Lipoprotein (a) and risk of ischemic stroke in the REGARDS study. Arterioscler Thromb Vasc Biol 39(4):810-818

52. Chen Y, Zhan X, Zhao Q, Wei X, Xiao J, Yan C et al (2019) Serum lipoprotein (a) and risk of hemorrhagic stroke among incident peritoneal dialysis patients: a large study from a single center in China. Ren Fail 41(1):800-807

53. Gorog DA (2010) Prognostic value of plasma fibrinolysis activation markers in cardiovascular disease. J Am Coll Cardiol 55(24):2701-2709

54. Gorog DA, Lip GYH (2019) Impaired spontaneous/endogenous fibrinolytic status as new cardiovascular risk factor?: JACC review topic of the week. J Am Coll Cardiol 74(10):1366-1375

55. Lijnen HR, Ds C (1996) Impaired fibrinolysis and the risk for coronary heart disease. Circulation 94(9):2052-2054

56. Urano T, Sakakibara K, Rydzewski A, Urano S, Takada Y, Takada A (1990) Relationships between euglobulin clot lysis time and the plasma levels of tissue plasminogen activator and plasminogen activator inhibitor 1. Thromb Haemost 63(1):82-86

57. Sumaya W, Wallentin L, James SK, Siegbahn A, Gabrysch K, Himmelmann A et al (2020) Impaired fibrinolysis predicts adverse outcome in acute coronary syndrome patients with diabetes: a PLATO sub-study. Thromb Haemost 120(3):412-422

58. Drabik L, Konieczyńska M, Undas A (2020) Clot Lysis Time Predicts Stroke During Anticoagulant Therapy in Patients with Atrial Fibrillation. Can J Cardiol 36(1):119-126

59. Longstaff $C$ (2018) Measuring fibrinolysis: from research to routine diagnostic assays. J Thromb Haemost 16(4):652-662 
60. Pieters M, Philippou H, Undas A, de Lange Z, Rijken D, Mutch N (2018) An international study on the feasibility of a standardized combined plasma clot turbidity and lysis assay: communication from the SSC of the ISTH. J Thromb Haemost 16(1007):1012

61. Thakur M, Ahmed AB (2012) A review of thromboelastography. Int J Periop Ultrasound Appl Technol 1(1):25-29

62. Chen A, Teruya J (2009) Global hemostasis testing thromboelastography: old technology. New Appl Clin Lab Med 29(2):391-407

63. Young G, Zhang R, Miller R, Yassin D, Nugent DJ (2010) Comparison of kaolin and tissue factor activated thromboelastography in haemophilia. Haemophilia 16(3):518-524

64. Zambruni A, Thalheimer U, Leandro G, Perry D, Burroughs AK (2004) Thromboelastography with citrated blood: comparability with native blood, stability of citrate storage and effect of repeated sampling. Blood Coagul Fibrinol 15(1):103-107

65. Thalheimer U, Triantos CK, Samonakis DN, Zambruni A, Senzolo $M$, Leandro $\mathrm{G}$ et al (2008) A comparison of kaolin-activated versus nonkaolin-activated thromboelastography in native and citrated blood. Blood Coagul Fibrinol 19(6):495-501

66. Davenport R, Khan S (2011) Management of major trauma haemorrhage: treatment priorities and controversies. $\mathrm{Br} \mathrm{J}$ Haematol 155(5):537-548

67. Maclvor D, Rebel A, Hassan Z-U (2013) How do we integrate thromboelastography with perioperative transfusion management? Transfusion 53(7):1386-1392

68. Shore-Lesserson L, Manspeizer HE, DePerio M, Francis S, VelaCantos F, Ergin MA (1999) Thromboelastography-guided transfusion algorithm reduces transfusions in complex cardiac surgery. Anesth Analg 88(2):312-319

69. Whiting D, DiNardo JA (2014) TEG and ROTEM: technology and clinical applications. Am J Hematol 89(2):228-232

70. Brown W, Lunati M, Maceroli M, Ernst A, Staley C, Johnson $R$ et al (2020) Ability of thromboelastography to detect hypercoagulability: a systematic review and meta-analysis. J Orthop Trauma 34(6):278-286

71. Okafor ON, Gorog DA (2015) Endogenous fibrinolysis: an important mediator of thrombus formation and cardiovascular risk. J Am Coll Cardiol 65(16):1683-1699

72. Pepperell D, Morel-Kopp M-C, Ward C (2014) Clinical application of fibrinolytic assays. Fibrinolysis and thrombolysis. pp. 125-62.

73. Yamamoto J, Inoue N, Otsui K, Ishii H, Gorog DA (2014) Global Thrombosis Test (GTT) can detect major determinants of haemostasis including platelet reactivity, endogenous fibrinolytic and thrombin generating potential. Thromb Res 133(5):919-926

74. Saraf S, Christopoulos C, Salha IB, Stott DJ, Gorog DA (2010) Impaired endogenous thrombolysis in acute coronary syndrome patients predicts cardiovascular death and nonfatal myocardial infarction. J Am Coll Cardiol 55(19):2107-2115

75. Christopoulos C, Farag M, Sullivan K, Wellsted D, Gorog DA (2017) Impaired thrombolytic status predicts adverse cardiac events in patients undergoing primary percutaneous coronary intervention. Thromb Haemost 117(3):457-470. https://doi.org/ 10.1160/TH16-09-0712

76. Otsui K, Gorog DA, Yamamoto J, Yoshioka T, Iwata S, Suzuki A et al (2015) Global thrombosis test - a possible monitoring system for the effects and safety of dabigatran. Thromb J 13:39

77. Spinthakis N, Gue Y, Farag M, Srinivasan M, Wellsted D, Arachchillage DRJ et al (2019) Apixaban enhances endogenous fibrinolysis in patients with atrial fibrillation. EP Europace 21(9):1297-1306

Publisher's Note Springer Nature remains neutral with regard to jurisdictional claims in published maps and institutional affiliations. 